\title{
A CRISE NO SISTEMA PRISIONAL BRASILEIRO
}

\author{
Thiago Vieira da Cunha Pereira ${ }^{1}$ \\ Rafaela Espinosa Peres ${ }^{2}$ \\ Keilor Dasilva de Sousa ${ }^{3}$
}

RESUMO: O presente artigo trata-se de um estudo sobre A crise no sistema prisional brasileiro. Por meio de uma revisão de literatura com pesquisa bibliográfica em que se busca informações em livros, revistas, publicações e demais materiais sobre o assunto. Entre os objetivos está à busca de maiores informações sobre o tema. O sistema prisional brasileiro vem apresentando nos últimos anos um aumento considerável de encarcerados, local esse que objetiva a ressocialização do apenado não vem conseguindo desenvolver seu papel, pois trata-se de um local onde seus direitos básicos assegurados por lei são diariamente desrespeitados.

Palavras-chave: Crise. Sistema Prisional. Ressocialização.

\section{INTRODUÇÃO}

O sistema prisional brasileiro desde seus primórdios até a atualidade vem apresentando um vasto crescimento da população carcerária e apesar da construção de novos presídios e da criação de novas vagas, estas não foram suficientes o que acarreta um sistema prisional superlotado.

Por estar privado de sua liberdade o preso encontra-se em uma situação especial a qual condiciona-o a uma limitação dos direitos previstos na Constituição Federal e nas Leis, o Estado além de ser responsável pela sua guarda e integridade, fica obrigado a lhe assegurar tais direitos como, assistência material, saúde, educacional, jurídica entre outros, no entanto o que se assiste nos presídios é uma realidade totalmente diferente.

Os Direitos Humanos fundamentados pela Constituição Federal visam resguardar o mínimo de dignidade ao indivíduo, no entanto a dignidade não é algo que se presencia nos presídios brasileiros, muitos não oferecem mais do que condições sub humanas, o que viola diretamente os Direitos Humanos.

O trabalho possui cunho qualitativo, realizado a partir de pesquisa bibliográfica e documental.

\footnotetext{
' Policial Penal, licenciado em Geografia pela UFPEL

2 Policial Penal, formada em Direito pela FURG.

3 Policial Penal, formado em Direito pela UCPEL.
} 


\section{DESENVOLVIMENTO}

O sistema prisional brasileiro vem apresentando-se caótico de condições e desigualdades, chamando a atenção principalmente quanto ao tratamento desumano ao qual milhares de detentos são submetidos.

O sistema carcerário é denominado como o conjunto de prisões, presídios e cadeias em um determinado território nacional, na sua maioria são financiados pelos governos estaduais com verba repassada pelo governo federal. O sistema é conduzido por regras internas, assim como aquele que cometeu um crime irá cumprir sua pena recebendo uma reeducação, para que possa se reestabelecer novamente na sociedade e tenha uma nova chance de construir algo e agir de forma correta perante a Lei, porém no Brasil não é o que se vê.

Em sua maioria as unidades prisionais representam para os detentos um inferno, pois os reclusos encontram-se em celas sujas, úmidas, anti-higiênicas e com uma capacidade desproporcional de pessoas, os mesmos são tratados como animais e isso acaba provocando uma eclosão de violência e abusos sexuais.

O Estado possui o direito de prender qualquer pessoa que infrinja a Lei, com base na proteção dos bens jurídicos os quais são tutelados por ele mesmo, no intuito de manter uma sociedade que seja harmônica, pacífica e justa para todos os cidadãos.

O direito penal é estabelecido para regular as condutas humanas e para isso são instituídas penas às pessoas que transgrediram as regras de não fazer as que estão contidas no Código Penal e nas Leis Penais, no entanto elas regulamentam também as garantias fundamentais pois elas fazem parte da constituição do Estado.

\footnotetext{
As garantias legais previstas durante a execução da pena, assim como os direitos humanos do preso estão previstos em diversos estatutos legais. Em nível mundial existem várias convenções como a Declaração Universal dos Direitos Humanos, a Declaração Americana de Direitos e Deveres do Homem e a Resolução da ONU que prevê as Regras Mínimas para o Tratamento do Preso. Já em nível nacional, nossa Carta Magna reservou 32 incisos do artigo $5^{\circ}$, que trata das garantias fundamentais do cidadão, destinados à proteção das garantias do homem preso. Existe ainda em legislação específica - a Lei de Execução Penal - os incisos de I a XV do artigo 4I, que dispõe sobre os direitos infraconstitucionais garantidos ao sentenciado no decorrer na execução penal (ASSIS, 2016, p.4).
}

Infelizmente no Brasil ainda é predominante a teoria de que quanto mais pessoas estiverem presas, este será o melhor caminho, no entanto se prende muito e em diversas 
vezes sem necessidade, e devido à isso os estabelecimentos prisionais encontram-se superlotados.

É de conhecimento de todos que os detentos não são tratados nos estabelecimentos prisionais de forma humana, digna e respeitosa, junto a isso a precariedade do sistema no tratamento do apenado, o papel da ressocialização é de suma importância pois trata-se de uma maneira de conscientizar o detento de que ele cumpra a sua pena de forma digna e volte ao convívio social sendo um ser humano melhor do que quando ali entrou.

$\mathrm{O}$ aglomerado de pessoas no sistema prisional brasileiro em pequenos ambientes traz consigo outras complicações, devido a impossibilidade de separação em decorrência do crime cometido, pessoas que cometeram crimes leves acabam dividindo a cela com presos considerados altamente perigosos e esse fato acaba gerando enormes transtornos e complicações psicológicas.

\footnotetext{
A ressocialização não pode ser conseguida numa instituição como a prisão. Os centros de execução penal, as penitenciárias, tendem a converter-se num microcosmo no qual se reproduzem e se agravam as grandes contradições que existem no sistema social exterior (MIRABETE, 2002, p.24).
}

Qualquer ofensa à dignidade humana deve ser tratada como sendo uma ofensa aos fundamentos do Estado de Direito, e tal comportamento não pode ser tolerado em nenhuma instituição prisional do Brasil, a Lei de Execução Penal (LEP) traz em seu Art.40, que todas as autoridades do país devem respeitar a integridade mental e física dos condenados, bem como, dos presos provisórios.

O sistema prisional brasileiro mostra-se falido e a superlotação é um dos maiores problemas o que acaba ocasionando em um aumento da proliferação de doenças, violência entre os detentos, sendo elas física, psicológica ou sexual, os detentos acabam dormindo no chão de suas celas.

Outro problema são as facções criminosas que de certo modo controlam os presídios, diariamente são noticiados através dos meios de comunicações que traficantes ordenam de dentro dos presídios para crimes, como incêndios a ônibus, assassinatos de policiais entre outros, tendo isso em vista torna-se praticamente impossível o processo de ressocialização, assim como atender as necessidades básicas dos detentos, o que acaba aumentando a violência e as rebeliões. 
A falência de nosso sistema carcerário tem sido apontada, acertadamente, como uma das maiores mazelas do modelo repressivo brasileiro, que, hipocritamente, envia condenados para penitenciárias, com a apregoada finalidade de reabilitá-lo ao convívio social, mas já sabendo que, ao retornar à sociedade, esse indivíduo estará mais despreparado, desambientado, insensível e, provavelmente, com maior desenvoltura para a prática de outros crimes, até mais violentos em relação ao que o conduziu ao cárcere. (MIRABETE, 2008, p.89).

A ressocialização é extremamente importante para mudar esse quadro, e trata-se de uma reeducação do apenado através de tratamentos e projetos dentro da prisão para que após o cumprimento de sua pena possa se integralizar novamente à sociedade.

A cada dia as prisões ficam mais lotadas, e o Estado mostra-se omisso e negligente quanto a esta situação, deixando com que o sistema prisional chegue a um verdadeiro caos, essa negligencia acaba acarretando em inúmeros problemas, dentre os já citados, cabe destacar o uso de drogas que é cada vez maior e o uso de celulares, pois assim os detentos mentem contato com o mundo exterior comandado crimes.

Além dos fatores já mencionado acima, aliados a falta de segurança, acabam estimulando rebeliões. $\mathrm{O}$ abandono dos detentos por parte do Estado, vem contribuindo para o crime organizado e as facções criminosas, que acabam dominando o ambiente prisional, impedindo até mesmo que o Estado possa interferir, sendo assim as organizações criminosas acabam intensificando suas ações e utilizam o sistema carcerário tanto para a disseminação de ações violentas quanto o controle do crime organizado.

Quando se defende que os presos usufruam as garantias previstas em lei durante o cumprimento de sua pena privativa de liberdade, a intenção não é tornar a prisão um ambiente agradável e cômodo ao seu convívio, tirando dessa forma até mesmo o caráter retributivo da pena de prisão. No entanto, enquanto o Estado e a própria sociedade continuarem negligenciando a situação do preso e tratando as prisões como um depósito de lixo humano e de seres inservíveis para o convívio em sociedade, não apenas a situação carcerária, mas o problema da segurança pública e da criminalidade como um todo tende apenas a agravar-se. (ASSIS, 2007, p. 76).

Fica cada vez mais complexo desenvolver comportamentos positivos e progressos quando se trata da ressocialização e reinserção do apenado à sociedade, pois a coletividade enxerga o apenado como um monstro e criminoso, não acreditando na possibilidade de uma mudança, no entanto esses julgamentos dificultam o processo de ressocialização, e acabam os punindo com falta de oportunidades.

A sociedade cala-se e fica inerte diante da violação dos direitos humanos no sistema prisional, considerando na maioria das vezes justo o fato do detento receber um tratamento desumano. 


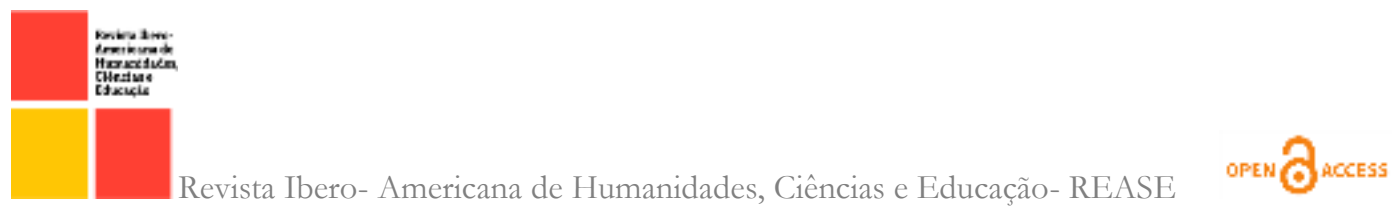

Cabe a sociedade uma mudança em seus pensamentos, pois tratam-se de vidas humanas, as quais não cabem ignorar e o discurso de aceitação perante a forma como são tratados, pois todos merecem um tratamento digno, independente de estar em liberdade ou em situação de privação.

O objetivo da pena, portanto, não é outro que evitar que o criminoso cause mais danos à sociedade e impedir a outros de cometer o mesmo delito. Assim, as penas e o modo de infligi-las devem ser escolhidos de maneira a causar a mais forte e duradoura impressão na mente de outros, como mínimo tormento ao corpo do criminoso. (BECCARIA, 1997).

Esse caos que encontra-se o sistema prisional atinge não somente os detentos, mas também as pessoas que estão em contato com tal realidade carcerária de forma indireta ou direta.

O sistema prisional brasileira precisa cumprir a legalidade, pois as condições desumanas e a precariedade em que os detentos vivem atualmente, trata-se de um assunto delicado, o qual vem repercutindo mundialmente.

A desestruturação do sistema prisional vem ocasionando o descrédito da prevenção e da reabilitação do detento, a LEP através do Art. 88, ressalva que o cumprimento da pena deve ocorrer em uma cela individual com área mínima de $6 \mathrm{mts}$ quadrados, o que não ocorre nos presídios nacionais.

Não é apenas a ação normativa do poder público que pode violar a
Constituição. A abstenção indevida do poder também pode desrespeitar o texto
supremo, dando ensejo ao reconhecimento da chama da
inconstitucionalidade por omissão. Noutro sentido, pode-se afirmar que a
necessidade de respeitar a Constituição não se satisfaz apenas com a atuação
positiva em conformidade com os seus preceitos. Hodiernamente, exige-semais,
pois omitir, total ou parcialmente, a aplicação de normas
constitucionais, quando a Constituição assim determina, também
constitui conduta inconstitucional (CUNHA JUNIOR, 2or6, p. 340).

A atual situação do sistema penitenciário brasileiro, nada mais é do que uma respostas para as rebeliões e fugas, que são observadas através da mídia e das redes sociais, assim como uma reposta pode-se considerar também como um alerta às autoridades para as condições desumanas as quais os detentos são submetidos, embora a legislação brasileira possua cunha protetivo.

A assistência ao preso e ao egresso possuem como objetivo principal prevenir o crime e orientar o seu retorno à sociedade, na verdade consiste em um apoio para reintegrar o detento novamente ao convívio social. 
No entanto é clara a falta de interesse por parte de nossos governantes para que realizem ações a fim de amenizar as condições desumanas em que encontram-se os detentos e cabe aqui salientar que o detento perde apenas o seu direito de ir e vir, os demais no entanto devem permanecer resguardados, pois os detentos não são culpados pela superlotação enfrentada pelo sistema penitenciário brasileiro atualmente.

Seria hipocrisia ou ingenuidade acreditar que a lei é feita para todo mundo em nome de todo mundo. É mais prudente reconhecer que ela é feita para alguns e se aplica a outros; que em princípio ela obriga os cidadãos, mas se dirige principalmente às classes mais numerosas e menos esclarecidas; que, ao contrário do que acontece nas leis políticas ou civis, sua aplicação não se refere a todos da mesma forma; que nos tribunais não é a sociedade inteira que julga um de seus membros, mas uma categoria social encarregada da ordem sanciona outra fadada à desordem. (...) A lei e a justiça não hesitam em proclamar sua necessária dissimetria de classe (FOUCAULT, 1999).

De certo modo a lei não está sendo executada como deveria, ocasionando diversas ociosidades dentro dos estabelecimentos penais como: violação dos direitos humanos, superlotação, violência entre os integrantes do sistema e por fim a frustrada ressocialização do preso.

O sistema penitenciário brasileiro vem mostrando-se ineficaz, onde o principal objetivo da pena de restrição da liberdade é retirar o criminoso do convívio social, punindo-o pelo crime praticado, e nesse sentido o Estado brasileiro é fragilizado, devido ao criminoso ser submetido a privação de liberdade, mas não a ressocialização.

Art. 12. A assistência material ao preso e ao internado consistirá no fornecimento de alimentação, vestuário e instalações higiênicas Art. I4. A assistência à saúde do preso e do internado de caráter preventivo e curativo, compreenderá atendimento médico, farmacêutico e odontológico. § $2^{\mathrm{o}}$ Quando o estabelecimento penal não estiver aparelhado para prover a assistência médica necessária, esta será prestada em outro local, mediante autorização da direção do estabelecimento. § 30 Será assegurado acompanhamento médico à mulher, principalmente no pré-natal e no pós-parto, extensivo ao recém nascido. (BRASIL, 1984).

As estruturas governamentais são falhas ao proporcionar medidas ressocializadoras, no entanto enorme parte da dificuldade em reinserir um indivíduo a vida em sociedade, está por parte da própria, a qual age com preconceito para com esses indivíduos, pois continuam acreditando que os mesmos não são capazes de viver em sociedade sem oferecer riscos ou cometer crimes, acabando não oferecendo oportunidades de emprego para que o indivíduo possa ter uma renda sem que precise recorrer a crimes para garantir sua existência. 
A sociedade possui uma cultura exteriorizada excluindo os indivíduos que sofreram condenações penais, os enxergando como pessoas que não devem ter proteção de seus direitos mesmo após estarem em liberdade e terem cumprido pena, porém esses sujeitos não deixam de ser pessoas com dignidade e humanidade.

A situação atual do sistema prisional, resultante da fragilidade da prisão se tornou um meio impeditivo de concretizar a reinserção do detento à sociedade.

A prisão não pode deixar de fabricar delinquentes. Fabrica-os pelo tipo da existência que faz os detentos levarem: que fiquem isolados nas celas, ou que lhes seja imposto um trabalho inútil, para o qual não encontrarão utilidade, é de qualquer maneira não pensar no homem em sociedade; é criar uma existência contra a natureza inútil e perigosa; queremos que a prisão eduque os detentos, mas um sistema de educação que se dirige ao homem pode ter razoavelmente como objetivo agir contra o desejo da natureza? A prisão fabrica também delinquentes impondo aos detentos limitações violentas; ela se destina a aplicar as leis, e a ensinar o respeito por elas; ora, todo seu funcionamento se desenrola no sentido do abuso de poder. Arbitrário da administração (FOLCAULT, 1999, p. 222).

O convívio dentro das penitenciárias acaba proporcionando o próprio aumento dos indicies de reincidência, bem como, o aumento da taxa de violência e o acúmulo de pessoas dentro das unidades prisionais. No entanto boa parte da dificuldade em reduzir a criminalidade, está na falta de amparo, amparo este que deve ser provido pelo Estado em conjunto com a sociedade, como maneira de prevenir a criminalidade.

Boa parte dos presos atualmente são pessoas analfabetas, pobres, de baixa escolaridade, negros, que sempre tiveram que conviver em meio ao crime.

O sistema prisional brasileiro vem se destacando pelo descumprimento dos princípios básicos de humanização da pena, fato esse que é mais um contribuinte para afastar a eficiência proposta pela LEP, visto que, a concretização da aplicação desses princípios, acabam com os pontos primordiais para a eficácia das garantias fundamentais à dignidade da pessoa humana e demais liberdades instituídas através da Constituição Federal.

O sistema penitenciário no Brasil é o retrato fiel de uma sociedade desigual, marcada pela ausência de políticas sociais para o enfrentamento das situações especificas da questão social, bem como pela falta de seriedade política na constituição da cidadania para milhares de homens e mulheres presos. A legislação em si é letra morta, sem o desenvolvimento de políticas sociais distributivas e universalizantes, principalmente para os extratos de baixa renda, que na maioria passam a compor uma parcela da população penitenciária brasileira (CAETANO, 2017, p. I). 


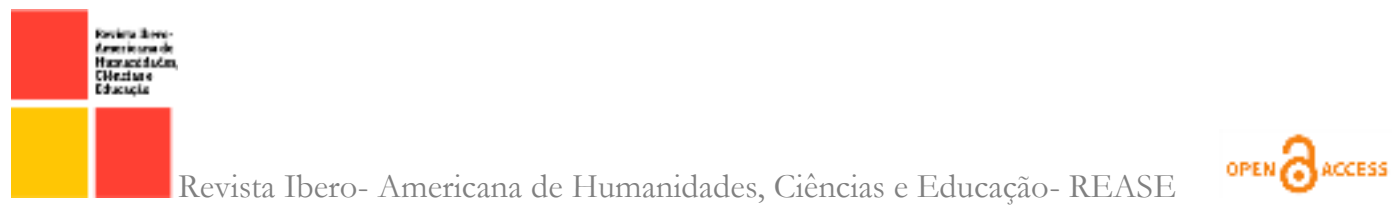

O sistema prisional brasileiro desde seus primórdios até a atualidade vem apresentando um vasto crescimento da população carcerária e apesar da construção de novos presídios e da criação de novas vagas, estas não foram suficientes o que acarreta em um sistema prisional superlotado.

A falência de nosso sistema carcerário tem sido apontada, acertadamente, como uma das maiores mazelas do modelo repressivo brasileiro, que, hipocritamente, envia condenados para penitenciárias, com a apregoada finalidade de reabilitá-lo ao convívio social, mas já sabendo que, ao retornar à sociedade, esse indivíduo estará mais despreparado, desambientado, insensível e, provavelmente, com maior desenvoltura para a prática de outros crimes, até mais violentos em relação ao que o conduziu ao cárcere. (MIRABETE, p. 89, 2008).

O direito a saúde deve ser construído e desenvolvido através de políticas públicas, as quais são ações governamentais cujo objetivo é a prevenção e o combate ais diversos agravos a doenças em geral, que visem o acesso a tratamentos, recuperação e promoção da saúde a todos.

Outro fator preocupante são as péssimas condições de trabalho, segurança e saúde, a que os agentes penitenciários são obrigados a suportar em suas funções diárias. Ao invés da maioria dos agentes da segurança pública - diretores, agentes penitenciários e auxiliares de segurança pública, serem facilitadores da ressocialização e condutores da boa convivência carcerária, estes representantes do Estado torturadores dos detentos.

Contribuem para esse quadro alarmante a política criminal falha junto à má gestão pública do sistema prisional.

O aumento da criminalidade sé dá devido à falta de tratamento de determinantes sociais, econômicos e em saúde para a população no geral, o que desencadeia a criação de novos infratores e reincidentes, o que leva ao aumento da população carcerária gerando frutos da desigualdade social.

Pode-se aliar a isso as fraudes nas licitações para a construção de presídios o que contribui para o problema estrutural de cumprimento das penas. Os problemas iniciais são a falta de alimentação, qualidade da água e higiene, o que agrava-se posteriormente junto a violência manifesta das facções no tráfico interno de drogas e armas, o que transformam os presídios em uma universidade e comércio do crime, a qual legitima-se por uma política criminal repressiva, de segregação social e exclusão do Estado. 


\section{CONSIDERAÇÕES FINAIS}

O sistema prisional propõe-se a recuperar os apenados e prepara-los para que não haja reincidência, isso infelizmente não ocorre pois são absurdas a precariedade $e$ as condições sub humanas em que os detentos vivem nas penitenciárias brasileiras, a ressocialização torna-se cada vez mais distante pois seus direitos básicos não são respeitados.

Estamos diante da omissão Estatal perante a questão penitenciária, a inadequação da execução penal às normas mínimas, o desrespeito ao indivíduo encarcerado tudo isso faz do próprio Estado, o principal discriminador dos direitos fundamentais.

É preciso pensar em novas Políticas Públicas que assegurem de fato os Direitos Humanos, a construção de novos presídios desafogaria os demais, tornando possível um trabalho mais árduo para a ressocialização.

\section{REFERÊNCIAS BIBLIOGRÁFICAS}

ASSIS, Rafael Damasceno de. As prisões e o direito penitenciário no Brasil. 2016.

ASSIS, Rafael Damasceno. A Realidade atual do Sistema Penitenciário Brasileiro. Artigo Publicado na Revista CEJ, Brasília, Ano XI, n. 39, p. 74-78, out./dez. 2007. Disponível em http://www.cjf.jus.br/revista/numero39/artigoo9.pdf. Aceso em: 218 jan. 202I.

BECCARIA, C.Dos delitos e das penas São Paulo: Revista dos Tribunais. 1997

BRASIL. Constituição (1988). Constituição da República Federativa do Brasil. Brasília: DF; Senado

CUNHA JÚNIOR, Dirley da. Curso de Direito Constitucional. io. ed. Salvador: JusPODIVM, 2016.

FOLCAULT Michel. Vigiar e Punir. 28 ed. Petrópolis: Vozes, 1999

FOUCAULT, M. Vigiar e Punir. História da violência nas prisões. $30^{\mathrm{a}}$ ed. Petrópolis, Rio de Janeiro: Vozes, 2005.

MIRABETE, Julio Fabbrini. Execução Penal. ıo ed. São Paulo: Atlas, 2002;

MIRABETE, Julio Fabbrini. Execução penal. ir. ed. rev. e atual. São Paulo: Atlas, p.89, 2008. 